\title{
Construction and Analysis of the Cell Surface's Protein Network for Human Sperm-Egg Interaction
}

\author{
Soudabeh Sabetian Fard Jahromi and Mohd Shahir Shamsir \\ Department of Biological and Health Sciences, Faculty of Bioscience \& Medical Engineering, Universiti Teknologi Malaysia, \\ 81310 Johor, Malaysia \\ Correspondence should be addressed to Mohd Shahir Shamsir; shahir@utm.my
}

Received 16 June 2013; Accepted 10 July 2013

Academic Editors: J. P. de Magalhaes and M. S. Scott

Copyright ( 2013 S. S. Fard Jahromi and M. S. Shamsir. This is an open access article distributed under the Creative Commons Attribution License, which permits unrestricted use, distribution, and reproduction in any medium, provided the original work is properly cited.

\begin{abstract}
Sperm-egg interaction is one of the most impressive processes in sexual reproduction, and understanding the molecular mechanism is crucial in solving problems in infertility and failed in vitro fertilization. The main purpose of this study is to map the sperm-egg interaction network between cell-surface proteins and perform an interaction analysis on this new network. We built the first protein interaction network of human sperm-egg binding and fusion proteins that consists of 84 protein nodes and 112 interactions. The gene ontology analysis identified a number of functional clusters that may be involved in the sperm-egg interaction. These include G-protein coupled receptor protein signaling pathway, cellular membrane fusion, and single fertilization. The PPI network showed a highly interconnected network and identified a set of candidate proteins: ADAM-ZP3, ZP3-CLGN, IZUMO1-CD9, and ADAM2IZUMO1 that may have an important role in sperm-egg interaction. The result showed that the ADAM2 may mediate interaction between two essential factors CD9 and IZUMO1. The KEGG analysis showed 12 statistically significant pathways with 10 proteins associated with cancer, suggesting a common pathway between tumor fusion and sperm-egg fusion. We believe that the availability of this map will assist future researches in the fertilization mechanism and will also facilitate biological interpretation of sperm-egg interaction.
\end{abstract}

\section{Introduction}

Fertilization is the process in which sperm and egg recognize, bind, and fuse with each other. These interactions include the initial cell-cell adhesion followed by the membrane fusion between the two gametes [1]. During this process, many molecular interactions in the form of protein-protein interactions will mediate the sperm-egg binding process [2]. The acrosome is a large organelle in the sperm that secretes enzymes such as the serine protease and the acrosin which assist the sperm penetration into the extracellular matrix of the oocyte (the zona pellucida) [3]. Many prior researches have attempted to find the molecules that are involved in the binding and fusion process. For example, acrosin has been identified as an important factor in the binding process [4]. However, further research on acrosin-knockout mice showed that the interaction process can occur in absence of acrosin, suggesting that the interaction relationship between sperm and the egg is much more complex than previously thought [5]. Due to the various limitations of materials and difficulties in analyzing in vivo membrane protein-protein interactions (PPI), many efforts have failed to comprehensively elucidate the fusion mechanism, leaving the molecular interactions that mediate sperm-egg membrane fusion still poorly understood $[6,7]$. This challenge is augmented further as proteinprotein interactions can interact in many ways, ranging from direct physical associations among proteins in a complex to transient interactions that occur among members of certain protein pathways [8].

The molecular interactions that mediate sperm-egg membrane fusion are yet to be mapped as there is no complete PPI network between the sperm and the oocyte proteins $[7,9]$. In this study, we constructed and analyzed a protein-protein interaction (PPI) network of all the membrane and surface proteins of the sperm and the oocyte proteins, identifying the essential PPI and their biological roles in the sperm-egg 
binding and fusion process. These analyses help us in better understanding of mechanism aspects of protein-protein interactions during the sperm-egg interaction process.

\section{Methods}

2.1. Selection of Proteins Expressed in Human Egg and Sperm. UniProt (http://www.uniprot.org/) was used to find human egg/oocyte and sperm related proteins with keywords "egg/oocyte" and "sperm." Subsequently the proteins that are expressed in human were selected. Each of the proteins UniProt ID was submitted to the STRING database (http://string-db.org/) and each protein-protein interaction was retrieved. The STRING database consists of known and predicted protein interactions that include direct (physical) and indirect (functional) associations. STRING quantitatively integrates interaction data from four different sources: genomic context, high-throughput experiments, coexpression, and prior knowledge from research publications [10-15].

2.2. Construction of the PPI Network. To create the sperm-egg interaction map, we compared the UniProt ID from sperm and egg maps to determine overlapping ID nodes between the sperm and the egg using the UltraCompare Professional 8.10 [16-18]. The overlapping ID nodes were then used to construct a sperm-egg PPI network in Cytoscape 2.8.2 [19]. By this method, we were able to consider all the specific possible interactions involved in the sperm-egg interaction.

2.3. Selection of the Proteins Associated with Cell Surfaces and Membrane Organization. The LOCATE database (http://locate.imb.uq.edu.au/) is a curated database that identifies and describes the membrane organization of proteins from mouse and human protein sequence sets. The UniProt IDs of the overlapping proteins in the sperm-egg PPI network were submitted to the LOCATE server to identify the proteins that are associated with cell surfaces and membrane organizations.

2.4. Clustering of PPI Networks. The final proteins datasets that have been filtered as associated with sperm-egg interaction and have been identified as involved in membrane organization were loaded into Cytoscape 2.8.2 and analysed using the AllegroMCODE plugin in Cytoscape. The AllegroMCODE plugin is a high performance fast algorithm that is used to detect clusters in a large protein network. Clusters in the network can be considered as protein complexes and functional modules, which can be identified as highly interconnected subgraphs [20]. The cluster analysis of the largest component in the network will enable the identification of important protein complexes and pathways.

2.5. Gene Ontology (GO) Enrichment Analysis. The clusters that have been identified using AllegroMCODE algorithm are then analyzed for their gene ontology using the BiNGO plugin in Cytoscape. The BiNGO plugin was used to identify the main ontologies in the protein network: molecular function, biological process, and cellular components [21].

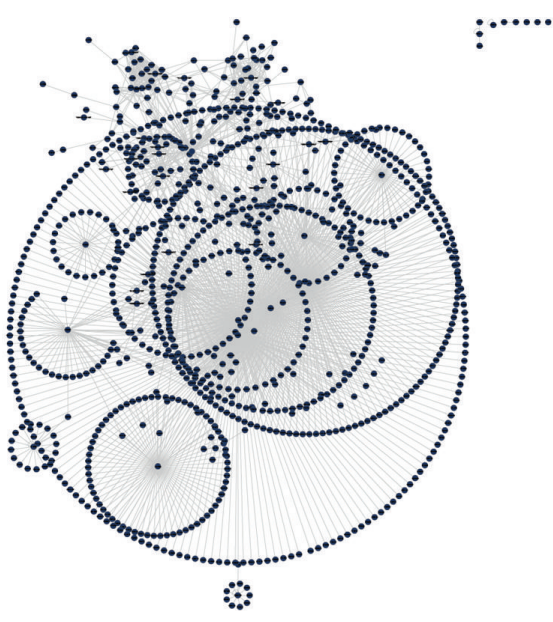

Figure 1: The PPI network of human egg related proteins in Cytoscape 2.8.2: this map involves 1056 proteins and 1700 interactions between these proteins.

2.6. DAVID (Database for Annotation, Visualization, and Integrated Discovery) v6.7 Analysis. DAVID v6.7 is a webaccessible program that provides a comprehensive set of functional annotation tools to understand the biological meaning behind large datasets of genes or proteins [22]. The identified UniProt IDs of proteins from the LOCATE database that are associated with cell surfaces and membrane of the overlapping network were submitted to DAVID to analyze the protein domains and pathways (Table 4).

\section{Results and Discussion}

Various researches have managed to identify the various molecules that are involved in sperm-egg binding and fusion. Most of these attempts have been focused on important factors in sperm-egg fusion in mammals, especially on the role of acrosin in the sperm penetration into the zona pellucida (ZP) $[5,6,9,23]$. Many previous efforts have studied the PPI network to find novel interaction, important molecular function, essential biological process, and potential drug targets [19, 24-27]. Predicting molecular complexes from protein interaction data is important because it provides another level of functional annotation above other guilt-by-association methods. Since subunits of a molecular complex generally function towards the same biological goal, prediction of an unknown protein as part of a complex also allows increased confidence in the annotation of that protein [28].

3.1. Selection, Construction, and Clustering of the PPI Network. The initial selection of proteins that are associated with human sperm and egg from the UniProt database produced 1056 proteins for egg and 6450 for sperm. The PPI interaction for egg is represented in Figure 1 and for sperm in Figure 2. Overall, there are significantly more PPI related to the sperm than to the egg. Examination of the PPI data showed that there are 1700 interactions in egg and 34,579 interactions in sperm. 


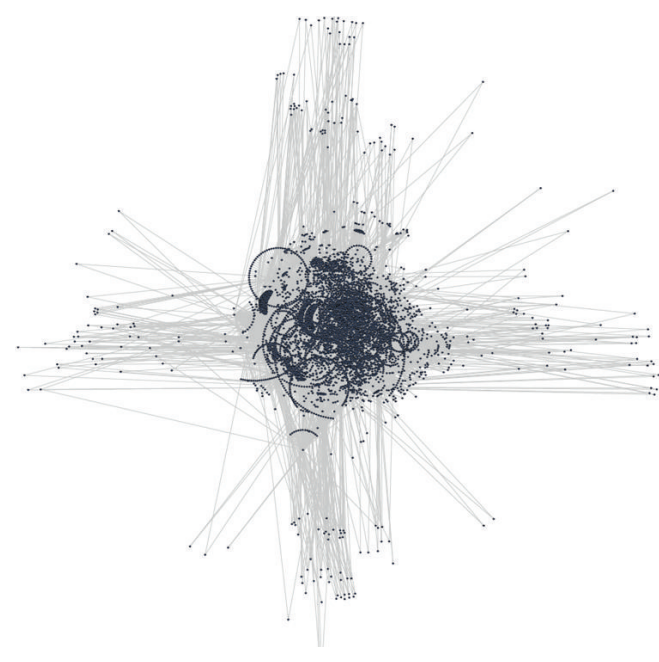

FIgURE 2: The PPI network of human sperm related proteins in Cytoscape 2.8.2: this map involves 6450 proteins and 34579 interactions between the proteins.

Selection of the overlapping protein ID nodes between the sperm and the egg proteins using UltraCompare Professional 8.10 showed 725 overlapping proteins with 2173 interactions between them. Filtering the overlapping protein nodes using LOCATE database identified 84 protein nodes that are associated with the cell's surfaces and membranes (Figure 3 ).

Membrane organization analysis using LOCATE database showed that the 84 identified proteins are associated with the cell's surface and plasma membrane. 14 proteins were identified as soluble proteins that include 7 secreted proteins, and 63 proteins were membrane proteins including 20 type I, 21 type II, and 22 multipass membrane proteins (Table 1).

The PPI network of the 84 protein nodes was extracted from the overlapping PPI network in Figure 3 and presented in Figure 4. This smaller PPI network of cell's surface and membrane proteins showed 112 interactions between them. The AllegroMCODE algorithm revealed three densely interconnected clusters that may represent molecular complexes within the PPI network that may participate in different aspects of sperm-egg interaction process (Figure 4) and are listed in Table 2.

Using the BiNGO plugin for Cytoscape, we identified the most significant GO biological process within the membrane and surface PPI (Table 3 ). The result showed that the largest cluster contains proteins that participate in the G-protein coupled receptor protein signaling pathway (GO: 0007186). G-protein coupled receptors (GPCRs) are a group of seven transmembrane proteins which bind signal molecules outside the cell, transduce the signal into the cell, and trigger a cellular response. The GPCRs work with the help of a G-Protein which binds to the energy-rich GTP [29].

The proteins identified within the most interconnected cluster are the $\mathrm{C}-\mathrm{C}$ chemokine receptor type 1 (CCR1) and type 3 (CCR3), G-protein coupled estrogen receptor 1 (GPER), and the extracellular calcium-sensing receptor
TABLE 1: Membrane organization analysis of interacting proteins using LOCATE database.

\begin{tabular}{ll}
\hline Protein class & Names of proteins \\
\hline $\begin{array}{l}\text { Soluble, } \\
\text { nonsecreted } \\
\text { protein (14) }\end{array}$ & CAPS1, GOPC, UQCC, FLOT1, TULP3, \\
\hline $\begin{array}{l}\text { Secreted protein } \\
(7)\end{array}$ & CTNB1, PTEN, AKT1 \\
\hline & UROK, FA11, LIPL, MMP2, FA5, PRTN3, \\
Type I membrane & ADA12, CADH1, CD22, CLGN, CXL16, \\
protein (20) & PTPRC, ERBB3, GPV, LDLR, PGH2, \\
& TF, TM190, TMEDA, TPA, TRBM, ZP2, \\
& ZP3, ZP4, IZUMO1 \\
& BCL2, COX41, CX7A2, FUT4, IGSF8, \\
Type II membrane \\
protein (21) & PDCD1, PPM1L, PTC1, STX1A, TM11E, \\
& TMPS6, TNF10, TNFA, \\
& USP9Y, UTY, VAMP1, VAMP2, VAMP8, \\
& VAPB, ZP1, ZPBP1 \\
\hline \multirow{3}{*}{$\begin{array}{l}\text { Multipass } \\
\text { membrane protein } \\
\text { (22) }\end{array}$} & ADAM2, CASR, CCR1, CD9, CDIPT, \\
& LTSR4, FSHR, GPER, HCN4, HHAT, \\
& P2Y13, PTC2, SMO, SYPL1, TX101, TXTP, \\
\hline
\end{tabular}

(CASR) protein and are all involved in the G-protein coupled receptor protein signaling pathway for the sperm-egg interaction. Theoretically, the human spermatozoon contains the mRNA coding for RANTES (regulated on activation and normally T-cell expressed and secreted) receptors CCR1 and expresses the CCR3 protein. The progesteroneenhanced hamster egg penetration test (HEPT) has shown that RANTES has a role in the sperm/oocyte fusion [30]. It is involved in the sperm-egg contact by increasing the intracellular calcium by causing the breakdown of plasma membrane polyphosphoinositides (PPI), which subsequently affects the production of inositol triphosphate (IP3). IP3 causes the release of calcium from internal stores, as it has been identified to occur in various cell types [31]. The spermatozoa that are lured to the egg by species specific chemoattractants are first made hypermotile by bicarbonateinduced cAMP signaling. Then, it is activated by egg-coat extracellular matrix ZP3 (zona pellucida) oligosaccharides that bind human specific galactosyltransferase on the sperm surface. Membrane clustering of these enzymes activates the sperm sensor GPCRs, causing transmembrane influx of sodium ions. This is followed by tyrosine phosphorylation of the $\mathrm{ZP} 3$ receptors, leading in turn to sperm pronuclear binding of the ZP3 receptor in the inner membrane leaflet [32].

The most important biological process identified for cluster 2 is the cellular membrane fusion (0006944). The cellular membrane fusion is a cellular process that joins two lipid bilayers to form a single membrane, a critical step in fusing the sperm and the egg [33]. The proteins identified within the cluster are the vesicle-associated membrane protein 8 (VAMP8) and synaptosomal-associated protein 23 (SNAP23). These proteins have been shown in laboratory 


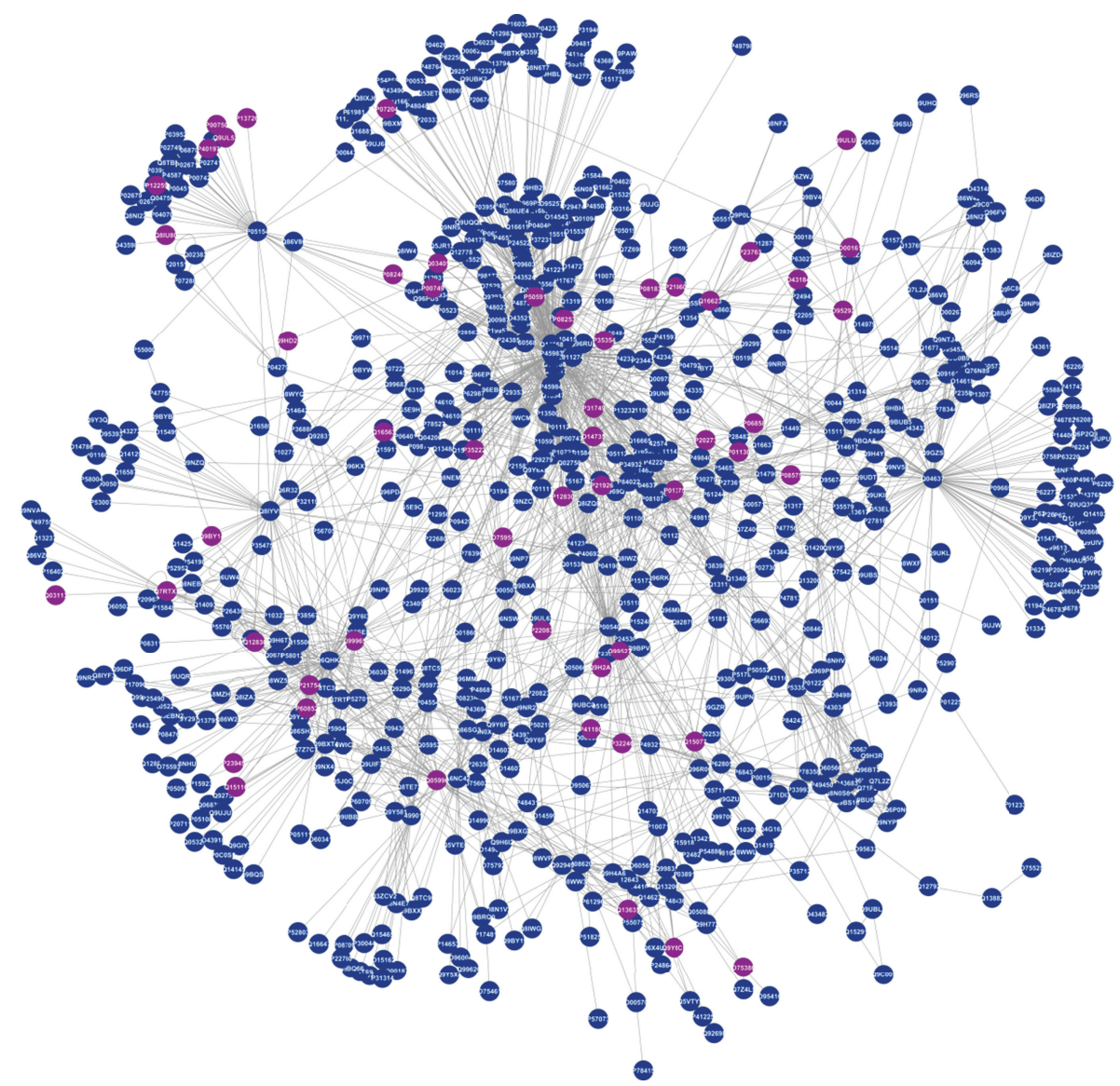

Figure 3: The PPI network of overlapping proteins rendered using Cytoscape 2.8 .2 showed 725 proteins and 2173 interactions between them. The 84 protein nodes highlighted in purple are membrane and surface proteins identified using the LOCATE database.

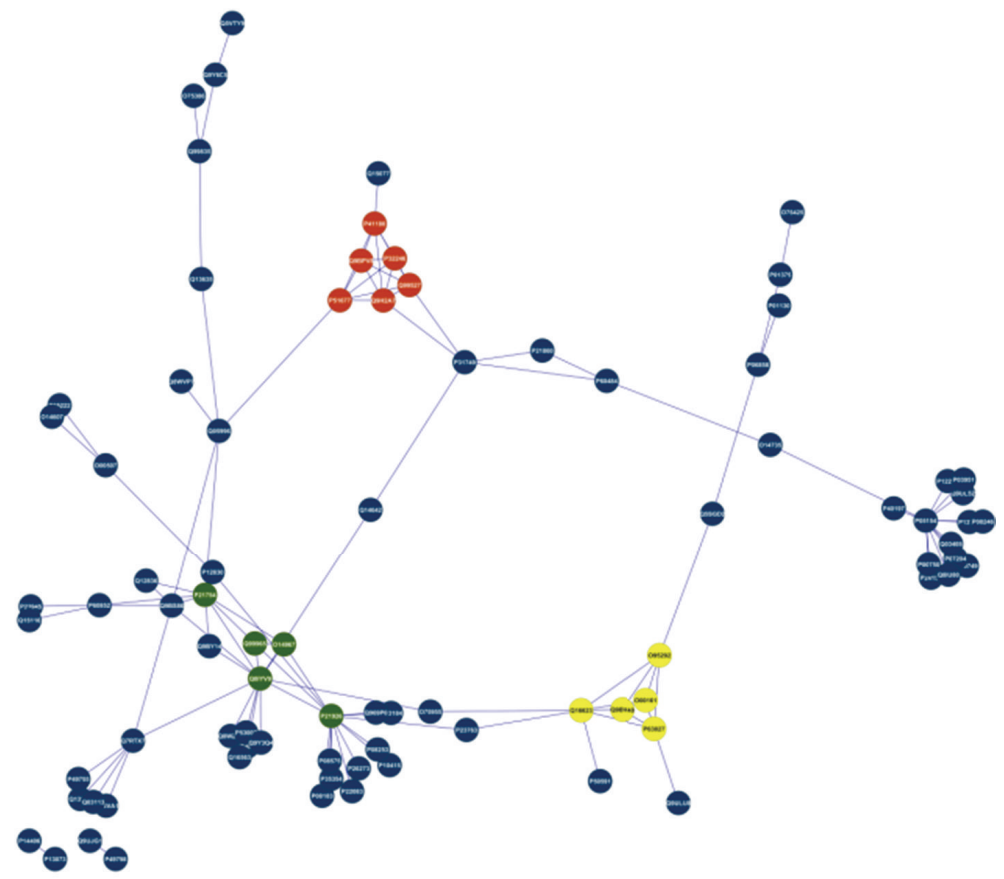

FIGURE 4: Sperm-egg interaction network was ranked as 1 to 3 clusters. Cluster 1, cluster 2, and cluster 3 are presented in red, yellow, and green, respectively. 
TABLE 2: The names of proteins and their respective classes in the three clusters.

\begin{tabular}{lcr}
\hline Clusters & Names of proteins & Protein class \\
\hline $\begin{array}{l}\text { Cluster } 1 \\
\text { (red in Figure 4) }\end{array}$ & CXL16 & $\begin{array}{c}\text { Type I membrane protein } \\
\text { Multipass membrane protein }\end{array}$ \\
\hline $\begin{array}{l}\text { Cluster } 2 \\
\text { (yellow in Figure 4) }\end{array}$ & CASR, CCR1, GPER, P2Y13, CCR3 & Soluble, nonsecreted protein \\
\hline $\begin{array}{l}\text { Cluster } 3 \\
\text { green in Figure 4) }\end{array}$ & SNP23 & Type II membrane protein \\
\hline
\end{tabular}

TABLE 3: The overrepresented GO biological process of each cluster.

\begin{tabular}{lccc}
\hline AllegroMCODE cluster ID & Description & Overrepresented GO code & $P$ value \\
\hline 1 (red in Figure 4) & G-protein coupled receptor & 0007186 & $1.6438 E-4$ \\
2 (yellow in Figure 4) & protein signaling pathway & 0006944 & $7.7391 E-5$ \\
3 (green in Figure 4) & Cellular membrane fusion & 0007338 & $1.2968 E-12$ \\
\hline
\end{tabular}

TABLE 4: Enriched DAVID pathways associated with sperm-egg interaction network.

\begin{tabular}{lccc}
\hline Pathways $(P \leq 0.05)$ & Count & $\%$ & $P$ value \\
\hline $\begin{array}{l}\text { hsa04610: complement and } \\
\text { coagulation cascades }\end{array}$ & 8 & 9.52 & $2.94 E-06$ \\
$\begin{array}{l}\text { hsa04130: SNARE } \\
\text { interactions in vesicular } \\
\text { transport }\end{array}$ & 5 & 5.95 & $4.08 E-04$ \\
$\begin{array}{l}\text { hsa05200: pathways in } \\
\text { cancer }\end{array}$ & 10 & 11.90 & 0.003 \\
$\begin{array}{l}\text { hsa05213: endometrial } \\
\text { cancer }\end{array}$ & 4 & 4.76 & 0.012 \\
$\begin{array}{l}\text { has05217: basal cell } \\
\text { carcinoma }\end{array}$ & 4 & 4.76 & 0.014 \\
$\begin{array}{l}\text { has05222: small cell lung } \\
\text { cancer }\end{array}$ & 4 & 4.76 & 0.044 \\
$\begin{array}{l}\text { has04640: hematopoietic } \\
\text { cell lineage }\end{array}$ & 4 & 4.76 & 0.046 \\
$\begin{array}{l}\text { has04210: apoptosis } \\
\text { has05215: prostate cancer }\end{array}$ & 4 & 4.76 & 0.048 \\
\hline
\end{tabular}

work as critical interacting proteins in membrane fusion and human sperm acrosome reaction [34].

The most important biological process of cluster 3 is the single fertilization (0007338). The single fertilization process is defined as the union of male and female gametes to form a zygote $[35,36]$. The proteins that are identified in the single fertilization PPI are the Izumo sperm-egg fusion protein 1 (IZUMO1), disintegrin and metalloproteinase domaincontaining protein 2 (ADAM2), calmegin (CLGN), CD9 antigen (CD9), and zona pellucida sperm-binding protein 3 (ZP3). The IZUMO1 in the sperm is an immunoglobulin superfamily member (with an immunoglobulin-like domain (Ig)) that is essential for sperm-oocyte fusion. CD9 may work by interacting with a sperm protein in trans (although data supporting this mode of action are minimal), by regulating other egg membrane proteins in cis, and/or through exosome-mediated release. ADAM2 has been implicated in sperm-egg binding and fusion [37]. Previous studies have demonstrated that calmegin $-/-$ sperms were defective in migrating into the oviducts and in binding to the egg plasma membrane [38]. As for the sperm-zona binding, the widely accepted involvement of sugar moiety on zona pellucida 3 (ZP3) is indicated to be dispensable by gene disruption experiments. In the sperm-egg fusion process, CD9 on egg and IZUMO1 on sperm have been identified as essential factors [5]. The overall analysis showed that 61 proteins $(72.6 \%)$ are associated with functions involving binding activity, acrosin binding, and serine-type peptidase and serine hydrolase activities that are all critical for spermegg interaction [6] (Figure 5).

3.2. Predicted Interactions and Candidate Proteins. The PPI in the three clusters may be important for the sperm-egg fusion (Figure 4). Some of these interactions have not been reported in previous experimental work and were inferred using prediction text mining, interologs mapping, and unspecific method coexpression. We identified five significant PPIs within the three clusters.

The PPI of P2Y13 in cluster 1 may be significant for spermegg interaction. The P2Y13 has been predicted to interact with CCR1, CCR3, CASR, CXL16, and GPER. However, this protein is yet to be detected in the ovary. It would be interesting to examine the role of P2Y13 in sperm-egg interaction. The second PPI is between ADAM2 and ZP3. The ADAM2 is found in sperm while the ZP3 is found in the egg. Previous studies using ADAM knockouts have shown reduced migration of sperm into the oviduct through the uterotubal junction, reduced binding to the $\mathrm{ZP}$, and/or reduced binding and fusion to the egg plasma membrane [7]. The third PPI is between ZP3 and calmegin (CLGN). The calmegin $-/-$ sperm has been shown to be defective when migrating into the oviducts and in binding to the egg plasma membrane. The fourth PPI is the interaction between IZUMO1 and CD9. IZUMO1 is essential for the sperm to 


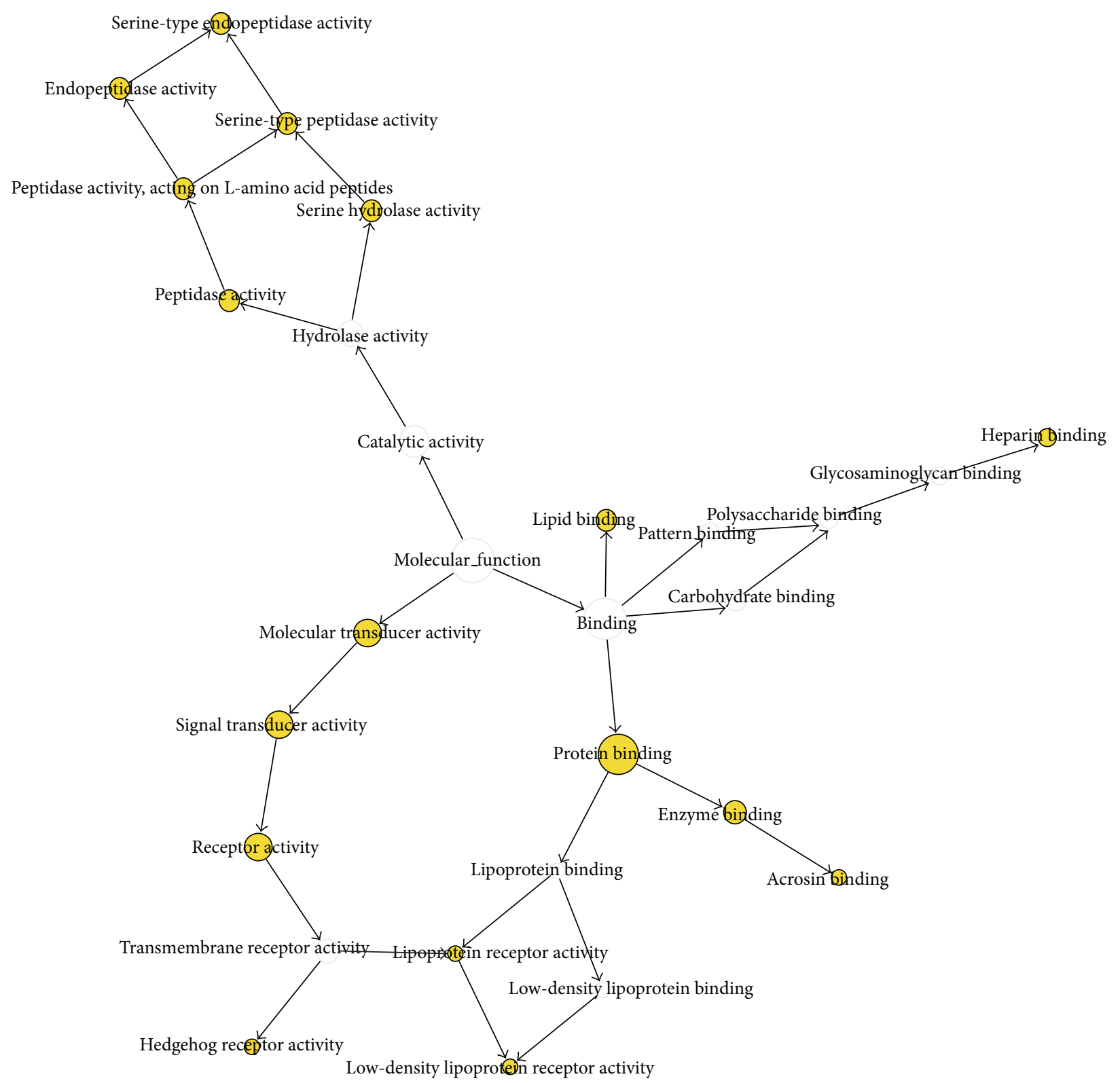

Figure 5: Molecular function map. Darker nodes refer to the significant ontologies of the dataset.

bind to eggs and that CD9 is essential for eggs to bind to sperm; therefore, it is tempting to speculate that they interact with each other to form a fusogenic complex. If these proteins do indeed interact, it is likely that they both require associating proteins on the sperm and egg cell surfaces, and the identity of these putative factors should be investigated [39]. The fifth PPI is between ADAM2 and IZUMO1. Chen and colleagues reported that the CD9 is a tetraspan protein that is associated with several betal integrins, including alpha6betal. Alpha6betal is present in eggs and interacts with the sperm-surface glycoprotein ADAM2 (fertilin beta) [40]. This result shows that ADAM2 may act as an interconnecting protein that mediates interaction between CD9 and IZUMO1.

For an overall overview of the interaction proteins, the functional analysis including domain analysis and pathway was performed using the tools in DAVID. The domain analysis using DAVID functional annotation tools included three subset databases: InterPro, PIR_Superfamily, and SMART databases, which showed 24, 4, and 6 statistically significant domains, respectively. These are the EGF-like region conserved sites (IPR013032, containing 7 proteins) that are involved in disulphide bonds, sperm binding glycoprotein ZP3-alpha domain (PIRSF002554, containing 2 proteins) involved in sperm-egg binding, and _Tryp_SPc domain (SMART:SM00020, containing 7 proteins) involved in the proteolysis and serine-type endopeptidase activity. These results showed some significant enriched domains that in the protein networks would regulate some aspects of interaction between sperm and egg. The functional significance of EGF domains in what appear to be unrelated proteins is not yet 
clear [41]. However, a common feature is that the repeats are found in the extracellular domain of membrane bound proteins or in proteins known to be secreted [42]. Evans et al. (1998) suggested a potential role of the cysteine-rich and/or EGF-like domains in sperm-egg adhesion [43], and the fusion peptide of the fertilin $\alpha$ protein was previously identified within the cysteine-rich domain [44]. In order to digest the zona pellucida glycoproteins, the acrosome organelle in the apical region of sperm head recognizes and binds with a single O-linked oligosaccharides chain, which is probably ZP3, and secretes enzymes such as serine protease and acrosin which help sperm penetration [45]. The KEGG analysis indicated that 12 statistically significant pathways were presented in sperm-egg PPI network. Interestingly, 10 proteins of the sperm-egg PPI network involved in spermegg interaction process were involved in the pathway in cancer [46]. These proteins are involved in prostate cancer, endometrial cancer, and small cell lung cancer. This suggests that fusion process in tumor growth and sperm-egg may share similar interactions.

\section{Conclusion}

We have created the first protein interaction network of human membrane and surface sperm-egg interaction proteins by using computational approach. The PPI network of sperm and egg showed the PPI map and revealed highly interconnected proteins, ranging from direct physical associations among proteins in a complex to transient interactions that occur among members of certain protein pathways. The analysis of the protein network enabled us to identify a set of candidate proteins important for the interaction between sperm and egg in human. We reported some predicted protein-protein interactions like ADAM-ZP3, ZP3-CLGN, IZUMO1-CD9, and ADAM2-IZUMO1 that may play an important role in sperm-egg interaction. These predicted interactions shows that ADAM2 may mediate interaction between two essential factors CD9 and IZUMO1. The association of $\mathrm{P} 2 \mathrm{Y} 13$ in sperm with a protein on plasma membrane of egg is entirely speculative.

KEGG analysis indicated that 12 statistically significant pathways were presented in sperm-egg PPI network. Interestingly, 10 proteins of the sperm-egg PPI network involved in sperm-egg interaction process were involved in the pathway in cancer, suggesting a common pathway between tumor fusion and sperm-egg fusion. The availability of this map will assist future researches studying the fertilization mechanism and will also facilitate biological interpretation of sperm-egg interaction.

4.1. Availability and Requirement. The sperm-egg PPI is available upon request. Contact: shahir@utm.my.

\section{Authors' Contribution}

The work was carried out in collaboration between all the authors. Mohd Shahir Shamsir defined the research theme. Soudabeh Sabetian Fard Jahromi designed methods and experiments, carried out the laboratory experiments, and analyzed the data. Both Mohd Shahir Shamsir and Soudabeh Sabetian Fard Jahromi interpreted the results and cowrote the paper.

\section{Acknowledgment}

The authors would like to acknowledge the Universiti Teknologi Malaysia Institutional Research Grant for the funding.

\section{References}

[1] G. B. Wortzman, A. J. Gardner, and J. P. Evans, "Analysis of Mammalian sperm-egg membrane interactions during in vitro fertilization," Methods in Molecular Biology, vol. 341, pp. 89-101, 2006.

[2] E. Rubinstein, A. Ziyyat, J.-P. Wolf, F. le Naour, and C. Boucheix, "The molecular players of sperm-egg fusion in mammals," Seminars in Cell and Developmental Biology, vol. 17, no. 2, pp. 254-263, 2006.

[3] A. Abou-Haila and D. R. P. Tulsiani, "Mammalian sperm acrosome: formation, contents, and function," Archives of Biochemistry and Biophysics, vol. 379, no. 2, pp. 173-182, 2000.

[4] D. Baba, S.-I. Kashiwabara, A. Honda et al., "Mouse sperm lacking cell surface hyaluronidase $\mathrm{PH}-20$ can pass through the layer of cumulus cells and fertilize the egg," Journal of Biological Chemistry, vol. 277, no. 33, pp. 30310-30314, 2002.

[5] N. Inoue, M. Ikawa, and M. Okabe, "The mechanism of spermegg interaction and the involvement of IZUMO1 in fusion," Asian Journal of Andrology, vol. 13, no. 1, pp. 81-87, 2011.

[6] K. Kaji and A. Kudo, "The mechanism of sperm-oocyte fusion in mammals," Reproduction, vol. 127, no. 4, pp. 423-429, 2004.

[7] J. P. Evans, "Sperm-egg interaction," Annual Review of Physiology, vol. 74, pp. 477-502, 2012.

[8] R. Daulat, "Mechanisms of mammalian sperm-egg interaction leading to fertilization," Gynecology \& Obstetrics, vol. 2, article 5, 2012.

[9] I. A. Brewis, R. A. van Gestel, B. M. Gadella et al., "The spermatozoon at fertilisation: current understanding and future research directions," Human Fertility, vol. 8, no. 4, pp. 241-251, 2005.

[10] D. Szklarczyk, A. Franceschini, M. Kuhn et al., "The STRING database in 2011: functional interaction networks of proteins, globally integrated and scored," Nucleic Acids Research, vol. 39, Database issue, pp. D561-D568, 2011.

[11] L. J. Jensen, M. Kuhn, M. Stark et al., "STRING 8-a global view on proteins and their functional interactions in 630 organisms," Nucleic Acids Research, vol. 37, Database issue, pp. D412-D416, 2009.

[12] C. von Mering, L. J. Jensen, M. Kuhn et al., "STRING 7-recent developments in the integration and prediction of protein interactions," Nucleic Acids Research, vol. 35, no. 1, pp. D358D362, 2007.

[13] B. Snel, G. Lehmann, P. Bork, and M. A. Huynen, "String: a web-server to retrieve and display the repeatedly occurring neighbourhood of a gene," Nucleic Acids Research, vol. 28, no. 18, pp. 3442-3444, 2000.

[14] C. von Mering, M. Huynen, D. Jaeggi, S. Schmidt, P. Bork, and B. Snel, "STRING: a database of predicted functional associations 
between proteins," Nucleic Acids Research, vol. 31, no. 1, pp. 258261, 2003.

[15] A. K. Tomar, B. S. Sooch, and S. Yadav, "Computational analysis of Concanavalin A binding glycoproteins of human seminal plasma," Bioinformation, vol. 7, no. 2, pp. 69-75, 2011.

[16] X. Li, X. Wen, and X. Li, "Design and application of the ASN.1 module in the LTE-Uu interface protocol stack," in Proceedings of the International Conference on Educational and Information Technology (ICEIT '10), pp. V3149-V3152, Chongqing, China, September 2010.

[17] Y. Kano, N. Nguyen, R. Saetre et al., "Filling the gaps between tools and users: a tool comparator, using protein-protein interaction as an example," Pacific Symposium on Biocomputing, pp. 616-627, 2008.

[18] G. Móra, R. Farkas, G. Szarvas, and Z. Molnár, "Exploring ways beyond the simple supervised learning approach for biological event extraction," in Proceedings of the Workshop on Current Trends in Biomedical Natural Language Processing (BioNLP '09), pp. 137-140, Association for Computational Linguistics, 2009.

[19] P. Shannon, A. Markiel, O. Ozier et al., "Cytoscape: a software environment for integrated models of biomolecular interaction networks," Genome Research, vol. 13, no. 11, pp. 2498-2504, 2003.

[20] J. S. Yoon and W. H. Jung, "A GPU-accelerated bioinformatics application for large-scale protein interaction networks," in Proceedings of the APBC poster presentation, 2011.

[21] S. Maere, K. Heymans, and M. Kuiper, "BiNGO: a cytoscape plugin to assess overrepresentation of gene ontology categories in biological networks," Bioinformatics, vol. 21, no. 16, pp. 34483449, 2005.

[22] G. Dennis Jr., B. T. Sherman, D. A. Hosack et al., "DAVID: Database for Annotation, Visualization, and Integrated Discovery," Genome Biology, vol. 4, no. 5, article P3, 2003.

[23] A. Jégou, A. Ziyyat, V. Barraud-Lange et al., "CD9 tetraspanin generates fusion competent sites on the egg membrane for mammalian fertilization," Proceedings of the National Academy of Sciences of the United States of America, vol. 108, no. 27, pp. 10946-10951, 2011.

[24] U. Stelzl, U. Worm, M. Lalowski et al., "A human protein-protein interaction network: a resource for annotating the proteome," Cell, vol. 122, no. 6, pp. 957-968, 2005.

[25] S. A. Lee, T. T. Tsao, K.-C. Yang et al., "Construction and analysis of the protein-protein interaction networks for schizophrenia, bipolar disorder, and major depression," BMC Bioinformatics, vol. 12, supplement 13, article S20, 2011.

[26] A. F. Flórez, D. Park, J. Bhak et al., "Protein network prediction and topological analysis in Leishmania major as a tool for drug target selection," BMC Bioinformatics, vol. 11, no. 1, article 484, 2010.

[27] Z.-A. Mohamed-Hussein and S. Harun, "Construction of a polycystic ovarian syndrome (PCOS) pathway based on the interactions of PCOS-related proteins retrieved from bibliomic data," Theoretical Biology and Medical Modelling, vol. 6, no. 1, article 18, 2009.

[28] G. D. Bader and C. W. V. Hogue, "An automated method for finding molecular complexes in large protein interaction networks," BMC Bioinformatics, vol. 4, no. 1, article 2, 2003.

[29] M. J. Marinissen and J. S. Gutkind, "G-protein-coupled receptors and signaling networks: emerging paradigms," Trends in Pharmacological Sciences, vol. 22, no. 7, pp. 368-376, 2001.
[30] A. Barbonetti, M. R. C. Vassallo, C. Antonangelo et al., "RANTES and human sperm fertilizing ability: effect on acrosome reaction and sperm/oocyte fusion," Molecular Human Reproduction, vol. 14, no. 7, pp. 387-391, 2008.

[31] M. Whitaker, "Calcium at fertilization and in early development," Physiological Reviews, vol. 86, no. 1, pp. 25-88, 2006.

[32] R. J. Epstein, Human Molecular Biology: An Introduction To the Molecular Basis of Health and Disease, Cambridge University Press, 2003.

[33] R. Blumenthal and D. Dimitrov, Membrane Fusion, Wiley Online Library, 1999.

[34] C. N. Tomes, M. Michaut, G. D. Blas, P. Visconti, U. Matti, and L. S. Mayorga, "SNARE complex assembly is required for human sperm acrosome reaction," Developmental Biology, vol. 243, no. 2, pp. 326-338, 2002.

[35] P. M. Wassarman, "Mammalian fertilization: molecular aspects of gamete adhesion, exocytosis, and fusion," Cell, vol. 96, no. 2, pp. 175-183, 1999.

[36] C. Meslin, S. Mugnier, I. Callebaut et al., "Evolution of genes involved in gamete interaction: evidence for positive selection, duplications and losses in vertebrates," PLoS One, vol. 7, no. 9, Article ID e44548, 2012.

[37] D. A. Ellerman, C. Ha, P. Primakoff, D. G. Myles, and G. S. Dveksler, "Direct binding of the ligand PSG17 to CD9 requires a CD9 site essential for sperm-egg fusion," Molecular Biology of the Cell, vol. 14, no. 12, pp. 5098-5103, 2003.

[38] M. Ikawa, T. Nakanishi, S. Yamada et al., "Calmegin is required for fertilin $\alpha / \beta$ heterodimerization and sperm fertility," Developmental Biology, vol. 240, no. 1, pp. 254-261, 2001.

[39] M. Ikawa, N. Inoue, A. M. Benham, and M. Okabe, "Fertilization: a sperm's journey to and interaction with the oocyte," Journal of Clinical Investigation, vol. 120, no. 4, pp. 984-994, 2010.

[40] M. S. Chen, K. S. K. Tung, S. A. Coonrod et al., "Role of the integrin-associated protein CD9 in binding between sperm ADAM 2 and the egg integrin $\alpha 6 \beta 1$ : implications for murine fertilization," Proceedings of the National Academy of Sciences of the United States of America, vol. 96, no. 21, pp. 11830-11835, 1999.

[41] S. W. Zimmerman, G. Manandhar, Y.-J. Yi et al., "Sperm proteasomes degrade sperm receptor on the egg zona pellucida during mammalian fertilization," PLoS One, vol. 6, no. 2, Article ID e17256, 2011.

[42] C. G. Davis, "The many faces of epidermal growth factor repeats," New Biologist, vol. 2, no. 5, pp. 410-419, 1990.

[43] J. P. Evans, R. M. Schultz, and G. S. Kopf, "Roles of the disintegrin domains of mouse fertilins $\alpha$ and $\beta$ in fertilization," Biology of Reproduction, vol. 59, no. 1, pp. 145-152, 1998.

[44] C. P. Blobel, T. G. Wolfsberg, C. W. Turck, D. G. Myles, P. Primakoff, and J. M. White, "A potential fusion peptide and an integrin ligand domain in a protein active in sperm-egg fusion," Nature, vol. 356, no. 6366, pp. 248-252, 1992.

[45] R. D. Moreno, A. A. Laserre, and C. Barros, "Protease activity involvement in the passage of mammalian sperm through the zona pellucida," Biological Research, vol. 44, no. 2, pp. 145-150, 2011.

[46] X. Lu and Y. Kang, "Cell fusion as a hidden force in tumor progression," Cancer Research, vol. 69, no. 22, pp. 8536-8539, 2009. 

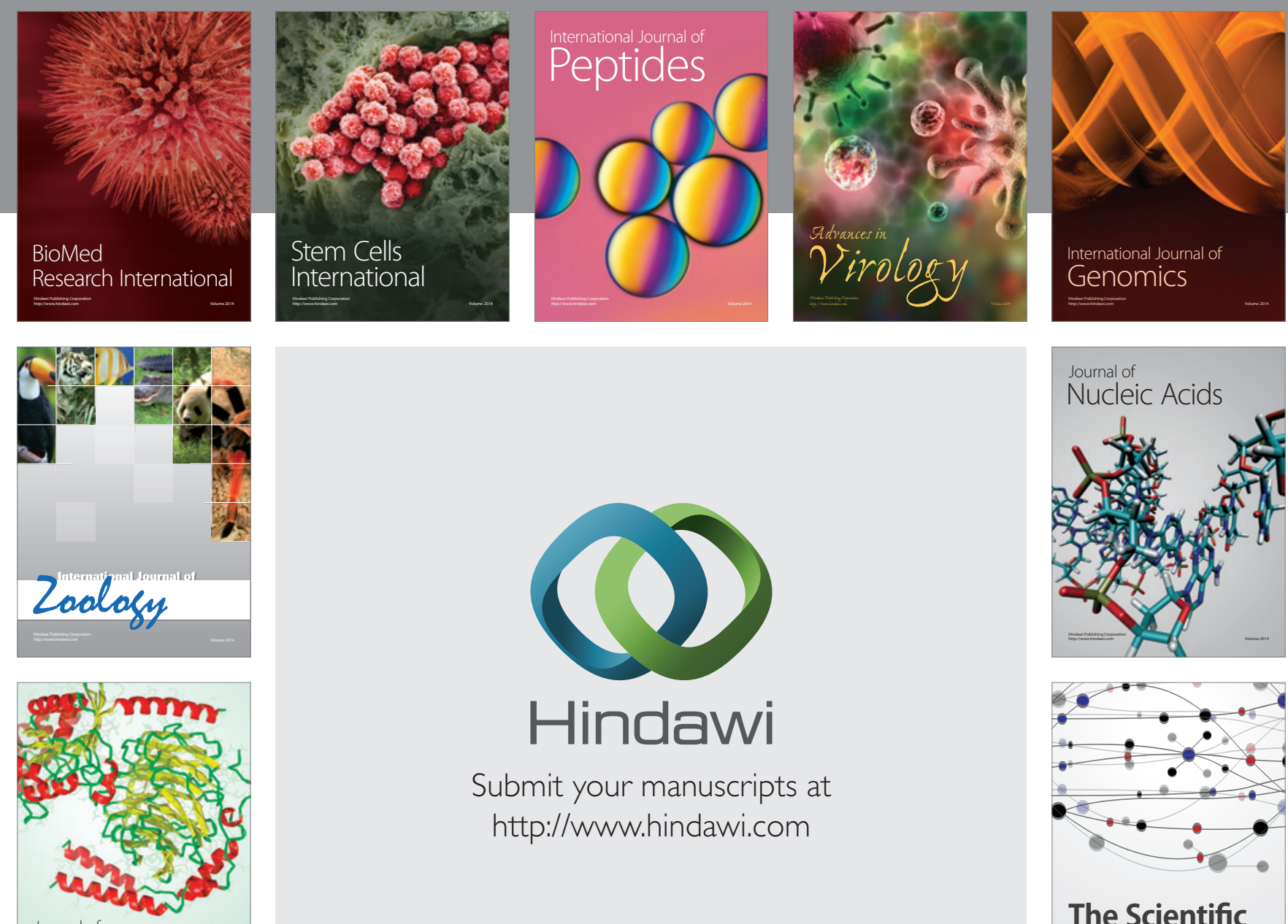

Submit your manuscripts at

http://www.hindawi.com

Journal of
Signal Transduction
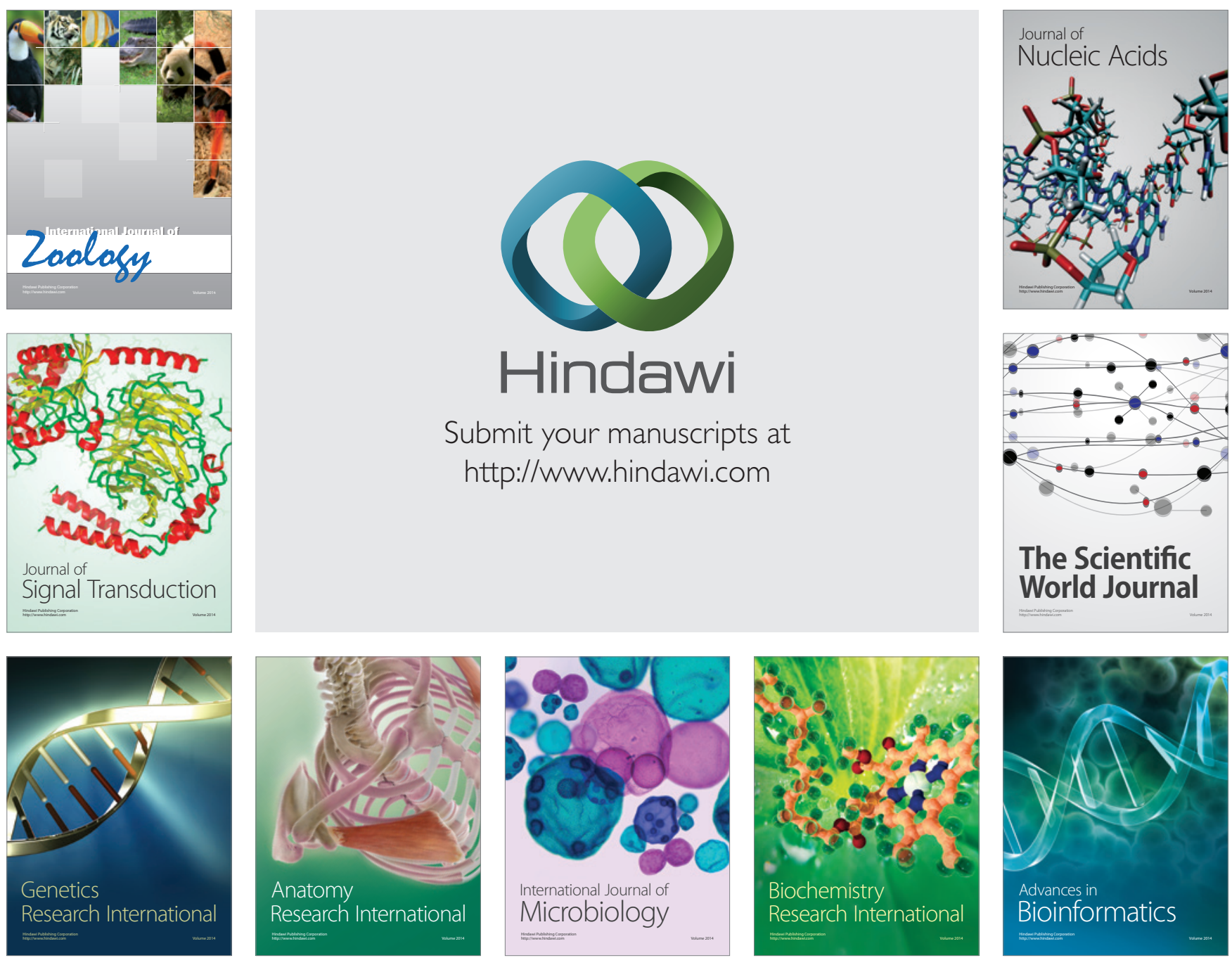

The Scientific World Journal
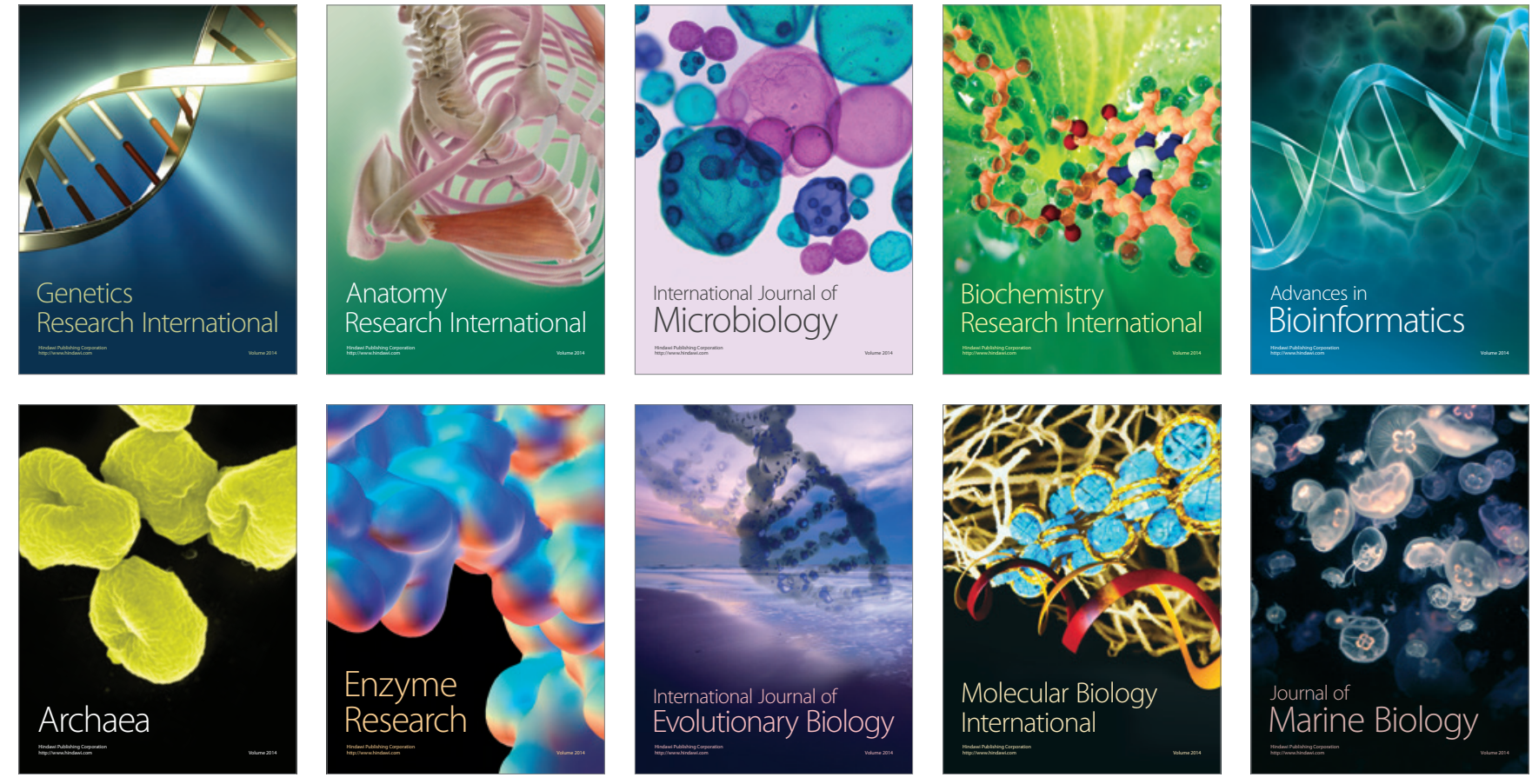